\title{
Can a targeted GP-led clinic improve outcomes for street sex workers who use heroin?
}

\author{
Jane Litchfield, Andrew Maronge, Tim Rigg, Benjamin Rees, Ravi Harshey and Jenny Keen
}

\begin{abstract}
Female street sex workers in the UK are often addicted to heroin, and sex work may be a result of the economic drive to fund this addiction. This study looks at outcomes of a primary care drugs treatment intervention for street sex workers who use heroin, using prescribed maintenance treatment with intensive health and psychosocial support. Thirty-four sex workers entered the study and $100 \%$ were retained in the study at 1 year. After 1 year, only $33 \%$ of participants were still sex workers. Quality of life had improved significantly and heroin use had reduced.

Keywords

drug misuse; heroin; primary care; prostitution; sex work.
\end{abstract}

\section{INTRODUCTION}

Up to $80 \%$ of street-level prostitution in the UK is driven by the need to finance drug addiction. ${ }^{1}$ The tackling of illicit drug use - and, therefore, the removal of the economic drive to prostitution - is considered to be vital to reducing the number of individuals involved in street sex work, a key objective stated in the UK government's coordinated prostitution strategy.

Engaging with drug-using sex workers is notoriously difficult ${ }^{2}$ and there is little published

J Litchfield, BMBS, F1 doctor, Chesterfield Royal Hospital, Derby. A Maronge, BMBS, F1 doctor, Kings Mill Hospital, Belper. T Rigg, BMBS, F1 doctor, University Hospital Lewisham, London. B Rees, BMBS, F1 doctor; R Harshey, BMBS, F2 doctor, University Hospitals, Nottingham. J Keen, $B A, M S c, M R C G P$, special lecturer, University of Nottingham Medical School at Derby, and clinical director, Primary Care Addiction Services, Sheffield.

Address for correspondence

Dr Jenny Keen, Primary Care Addiction Services, Guernsey House, 84 Guernsey Road, Sheffield, S2 4HG.

E-mail: j.keen@shef.ac.uk

Submitted: 23 October 2009; Editor's response: 10 December 2009; final acceptance: 9 February 2010.

(c)British Journal of General Practice 2010; 60: 514-516.

DOI: 10.3399/bjgp10X514774 evidence for best practice in the UK. However, a number of studies looking at drug-related prostitution have suggested that the best way to engage this group may be to offer treatment for drug problems in the first instance, with related services such as sexual health and psychosocial interventions being accessed through this primary intervention. ${ }^{3,4}$

This study looks at a targeted drug treatment programme for street sex workers within a GP-led primary care drug treatment setting in Derby, UK, in which a range of support services were offered once women had entered standard prescribed treatment for their heroin addiction.

\section{METHOD}

\section{Setting}

The Bradshaw Clinic is a GP-led primary care drug treatment service looking after approximately 1000 people who use heroin in Derby, a city with areas of deprivation in the formerly industrial midlands of the UK. It forms the hub of a network of GP shared-care practices in the city. The clinic opened in October 2006, staffed by GPs with special interest and specialist nurses supported by key workers.

The targeted sex workers' clinic was designed to provide a more intensive 'one-stop shop' for female sex workers who use heroin in order to offer them a range of medical, social, and drug treatment services including prescribed treatment for heroin addiction, contraception, and sexual-health interventions.

Referrals were invited from any source but came particularly from a local street agency offering nonmedical support and outreach to street sex workers. Once they had started on a prescribed treatment programme for their heroin use (usually methadone maintenance), patients were able to access sexual health interventions and advice, as well as specialised keyworking and psychosocial interventions as required.

Urine samples were routinely taken prior to treatment and at intervals thereafter, testing not only for illicit opiates, but also for compliance with prescribed substitute medication.

This study aims to measure the effectiveness of this 
targeted approach using questionnaires, structured interviews, and computerised record data at point of entry and at 1 year.

\section{Inclusion criteria}

All patients entering treatment in the street sex workers' clinic at the GP-led Bradshaw Clinic between October 2006 and May 2007 were eligible for entry in the study. Inclusion criteria were that:

- the participant was a female heroin user entering the specialist clinic; and

- the participant had offered sex for money within the previous 4 weeks.

The exclusion criteria were the same as those that applied to the clinical service: patients under the age of 18 years and those without a physiological addiction to heroin were excluded, but those with mental health and social problems were not.

\section{Recruitment and follow-up}

Participants were identified by clinicians and invited to take part. Each participant was met by a researcher at a routine clinic appointment and asked:

- to consent to records being accessed in order to look at their initial assessment on entry to the service and subsequent computerised records; and

- to be interviewed between October 2007 and May 2008 after 1 year in treatment.

Initial assessment data were converted into an entry-point Christo score (see below). Interviews at 1 year were conducted by the trained study team using the same assessment proforma as initial assessment to gain a comparative Christo score. Additional questions were asked to assess participants' involvement with street sex work at 1 year. Computerised records enabled access to records of urine samples taken over the 1-year period.

\section{Outcome measures}

The outcome measures used were quality of life (QoL) score, involvement in prostitution, and heroin use, using the following methods or tools:

- The Christo inventory. ${ }^{5}$ This is a widely used clinical tool validated as a QoL measure in people who use drugs, which can be used flexibly to score data obtained from multiple sources. It includes questions on drug use, general and mental health, housing, family, and social stability.

- Self-reported involvement in sex work in a structured interview.

\section{How this fits in}

There is very little research into the relationship between heroin use and street prostitution and, in particular, into the effects of heroin treatment on involvement in prostitution. A number of authors have suggested that treatment of drug problems is essential to enable people to exit prostitution. This unique study in a UK primary care based GP-led service supports the contention that prescribed treatment for drug problems can break the cycle and lead to positive outcomes, including exit from prostitution for some participants.

- Urine samples to show opiates other than the prescribed substitute medication (standard diagnostic test strips). The sample taken nearest to entry and that taken nearest to 1 year (+/- 1 month) were examined for each participant.

\section{Statistical analysis}

A paired $t$-test was used to look for a change in Christo score from the beginning of the study to its end.

\section{RESULTS}

\section{Participants}

Forty-two patients fulfilled the entry criteria. Six could not be included as researchers were unable to meet them to gain consent; two refused consent. Everyone who entered (34 patients) completed a year in the study.

\section{Principal findings}

Christo score. The mean Christo score reduced from 12.05 at entry to 8.97 at 1 year. The $P$-value is $<0.001$ - strong evidence to reject the null hypothesis that the Christo score stayed the same.

Involvement in sex work (self report). Of 34 women who were sex workers at the beginning of the study, only 11 (33\%) reported being involved at 1 year.

Heroin use (percentage of positive urine samples). Of 30 urine samples nearest to entry, $26(87 \%)$ were positive for heroin compared with 21 out of $29(72 \%)$ at 1 year (+/- 1 month).

\section{DISCUSSION}

\section{Summary of main findings}

Thirty-four street sex workers were successfully engaged with GP-led primary care drug treatment services in Derby for over a year - a significant number for such individuals that are both vulnerable and hard to access.

The clinic and its access to targeted primary care services was effective in significantly improving the health and wellbeing of the sample, as measured by the Christo score.

All responders were actively sex working at the beginning of the study, whereas, after a year of 
prescribed treatment for their heroin addiction, the proportion reporting involvement in sex work had dropped to $33 \%$. There is no apparent reason or incentive for participants to be less honest about this after 1 year than at entry, as their treatment was unaffected.

Heroin use, as reflected in urine samples, had reduced overall in the cohort, from $87 \%$ at entry to the study (the negative $13 \%$ of samples were taken after the start of treatment), to $72 \%$ at 1 year. The reduction to $72 \%$ at 1 year compares with around $50 \%$ still positive in studies undertaken with general, less chaotic populations. ${ }^{6}$

As urine sampling for illicit opiates is not quantitative and it was known that all participants were taking maintenance medication, it is likely that actual amounts of heroin used may have fallen much more than numbers of positive samples, as suggested in another study. ${ }^{6}$

In the context of an abstinence-based government treatment policy, it is pertinent to note that total abstinence from heroin use does not appear to be a precondition for stopping street sex work.

\section{Strengths and limitations of the study}

This study recruits a group of individuals that are notoriously hard to access and for which there is very little published data. It is also unusual in looking at outcomes for a GP-led primary care-based UK drug treatment service.

Retention in the study at 1 year was $100 \%$; as such, the study did not suffer from bias due to failure to track those who dropped out. On the other hand, it relies, to a large extent, on self-reported data. It is also important to note that, in this field, it is very difficult to carry out a randomised controlled study, as control participants are not available. This study, therefore, relies on repeated measures for a single self-selected cohort and confounding variables, such as readiness to change, cannot be excluded.

Regression to the mean would tend to reduce the number of sex workers and heroin users over time; it has not been possible to control for this effect. However, the results from this study are encouraging and suggest that further research in this field would be fruitful.

\section{Comparison with existing literature}

There are very few studies in this field. An observational study by DeBeck et al pointed to the economic relationship between intravenous drug use and income generation by prostitution, and noted that intervention to relieve financial pressure by involvement in treatment programmes should, on the face of it, be successful. A further study ${ }^{8}$ pointed to the improved take-up of a wider range of health promotion interventions, which is likely if these are embedded in a drug treatment programme and continued untreated illicit drug use is a barrier to exiting prostitution. ${ }^{9}$

\section{Implications for clinical practice}

The Home Office prostitution strategy ${ }^{1}$ recognises the range of health issues arising from prostitution and suggests an integrated approach to managing sex workers. However, the 2007 Department of Health guidelines on drug misuse management ${ }^{10}$ give no explicit advice for treating sex workers as a separate population that is vulnerable. This study indicates that GP-led primary care interventions, targeted specifically at treating opiate addiction in this group, can be effective not only in improving health and wellbeing, but also in achieving an end to working on the streets for some women.

\section{Funding body}

Statistical and academic support was funded by Department of General Practice, Nottingham University Medical School at Derby.

\section{Ethics approval}

Ethical approval for the study was given by the North Nottinghamshire Research Ethics Committee: 20/9/07, 07/HO407/53

\section{Competing interests}

The authors have stated that there are none. Jenny Keen was clinical director of the Bradshaw Clinic at the time of the study; she was not the lead GP for the sex workers' clinic.

\section{Acknowledgements}

With thanks to staff at the Bradshaw Clinic, Derby, and Professor Joe Kai (Professor of General Practice at the University of Nottingham at Derby).

\section{Discuss this article}

Contribute and read comments about this article on the Discussion Forum: http://www.rcgp.org.uk/bjgp-discuss

\section{REFERENCES}

1. Home Office. A coordinated prostitution strategy and a summary of responses to 'Paying the Price'. London: Home Office, 2006.

2. Hester M, Westmarland N. Tackling street prostitution: towards an holistic approach. Home Office Research Study 279. London: Home Office Research, Development and Statistics Directorate, 2004.

3. Smith FM, Marshall LA. Barriers to effective drug addiction treatment for women involved in street-level prostitution: a qualitative investigation. Crim Behav Ment Health 2007; 17(3): 163-170.

4. Expert Group on Prostitution in Scotland. Being outside: constructing a response to street prostitution. A report of the Expert Group on Prostitution in Scotland. Edinburgh: Scottish Executive, 2004.

5. Christo G, Spurrell S, Alcorn R. Validation of the Christo Inventory for Substance-misuse Services (CISS): a simple outcome evaluation tool. Drug Alcohol Depend 2000; 59(2): 189-197.

6. Keen J, Oliver P, Rowse G, Mathers N. Does methadone maintenance treatment based on the new national guidelines work in a primary care setting? Br J Gen Pract 2003; 53(491): 461-467.

7. DeBeck K, Shannon $\mathrm{K}$, Wood $\mathrm{E}$, et al. Income generating activities of people who inject drugs. Drug Alcohol Depend 2007; 91(1): 50-56.

8. Vivancos R, Maskrey V, Rumball D, et al. Crack/cocaine use in a rural county of England. J Public Health (Oxf) 2006; 28(2): 96-103.

9. Manopaiboon C, Bunnell RE, Kilmarx PH, et al. Leaving sex work: barriers, facilitating factors and consequences for female sex workers in northern Thailand. AIDS Care 2003; 15(1):39-52.

10. Department of Health (England) and the Devolved Administrations. Drug misuse and dependence: UK guidelines on clinical management. London: Department of Health (England), the Scottish Government, Welsh Assembly Government and Northern Ireland Executive, 2007. 